\title{
Application of an Enhanced Version of Recursive Operability Analysis for Combustible Dusts Risk Assessment
}

\author{
Marco Barozzi ${ }^{1}$, Sabrina Copelli ${ }^{1}$, Martina Silvia Scotton ${ }^{1}$ and Vincenzo Torretta ${ }^{2, *(1)}$ \\ 1 Department of Science and High Technology, Università degli Studi dell'Insubria, via Vico, 46, 21100 Varese, \\ Italy; marco.barozzi89@gmail.com (M.B.); sabrina.copelli@uninsubria.it (S.C.); \\ martina.scotton@gmail.com (M.S.S.) \\ 2 Department of Theoretical and Applied Sciences, Università degli Studi dell'Insubria, via Vico, 46, \\ 21100 Varese, Italy \\ * Correspondence: vincenzo.torretta@uninsubria.it
}

Received: 19 March 2020; Accepted: 26 April 2020; Published: 28 April 2020

check for updates

\begin{abstract}
Organic dust explosions were and are still today a critical issue in the food, pharmaceutical, and fine chemical industry. Materials such as flour, corn starch, sugar and APIs represent a cause of severe accidents. In this framework, we investigated a modified version of Recursive Operability Analysis-Incidental Sequence Diagrams (ROA-ISD), called ROA Plus-ISD, specifically tailored to describe industrial processes involving organic combustible dusts. Compared to more classical techniques such as Hazard and Operability (HazOp), ROA-ISD allows for a direct generation of fault trees, providing a useful tool to connect Qualitative with Quantitative Risk Analysis (QRA). ROA Plus-ISD is very similar to ROA-Cause Consequence Diagrams (CCD), which has already proven to be an effective tool to perform both risk assessment on existing plants and reconstructing already occurred accidents, given its logical structure and width of the application fields. In this work, we modified specific parts of the standard ROA-CCD method: (1) the Failure Mode and Operability Analysis (FMEA) database has been structured in order to retrieve the well-known explosion pentagon (for dusts) and all the instruments, devices, apparatuses and controllers typical of industries which process organic dusts; (2) a new comprehensive list of process variables has been compiled. In this way, it is possible to tailor the information required for the generation of the fault trees concerning top events involving mainly dust explosions and fires. This method has been implemented in order to reconstruct the dynamics of the February 2008 Imperial Sugar refinery plant accident (Port Wentworth, GA, USA). Results demonstrated the applicability of the enhanced method by highlighting the criticalities of the process already showed by a previously detailed reconstruction performed by the Chemical Safety Board.
\end{abstract}

Keywords: recursive operability analysis; dust explosion; safety engineering; risk assessment; fault tree analysis

\section{Introduction}

Industrial safety has been always considered of great interest and importance worldwide [1,2]. Particularly, in the process industry field, many efforts have been made in both legislation and implementation of safety systems/barriers to promote the mitigation of fatal accidents, such as fires, explosions and toxic releases. Risk mitigation in production facilities is still a matter of great interest, especially in activities that represent a serious hazard to human health, environment, and industrial plants. 
In the last decades, Quantitative Risk Analysis (QRA) [3,4] has become established as a paramount method to perform a risk assessment, given the possibility to associate an objective quantity (such as a probability) to an unwanted event. However, QRA is a general concept, and it does not automatically provide a specific technique or procedure to be followed. Usually, the analysis consists in several steps, including identification of accidental scenarios and estimation of both magnitude and probability of occurrence of undesired events [5]. Historically, several methods were proposed in order to perform better QRA. For what concerns the identification of an accidental scenario, the Hazard and Operability (HazOp) technique, introduced in 1983 by Kletz [6], was developed in order to classify process criticalities for the chemical industry, working around process variable deviations. Nowadays, it is still potentially the most used risk analysis method inside chemical companies. The HazOp method excels in identifying accidental scenarios and critical parts of the plant, and, given its well-defined scheme, it provides objective results. However, the information recorded from an HazOp analysis is a not structured list of causes and consequences of process variables deviations. For this reason, it is not a good tool to estimate accident probabilities, which is a core part of the risk index definition. Other methods have been proposed and developed, with the aim of improving risk estimation. The Failure Mode and Operability Analysis (FMEA), or the Failure Mode and Criticality Operability Analysis (FMECA) [5,7], are techniques dedicated to the identification of accidental scenarios based upon the failure modes of components present in process equipment, such as valves and switches. FMECA implements a criticality index, in addition to the classic FMEA, highlighting only the most crucial components of the plant. Hence, FMEA/FMECA, is a good tool to find the components involved in potential accidents, and usually, the associated failure rates can be recovered from a literature database. However, it still provides unstructured information, leaving unknown an accidental scenario probability estimation. For the estimation of probabilities, which are required for the risk index assessment, Fault Tree Analysis (FTA) [8,9] is among the most used methods, given its high flexibility in the application field. FTA requires a combination of basic events connected through logic gates. This task can be quite complicated to be performed, especially inside complex plants with a lot of human interactions with the system. It is clear then, that a risk assessment can be effective if it is obtained through the synergy of many methods, each one dedicated to describing specific risk analysis steps.

In this framework, several integrated methods have been thoroughly developed and presented, such as MAXCRED [10], SCAP [11]. The purpose of such methods is to both identify likely accidental scenarios in chemical industries, such as fires and explosions, addressing the magnitude of accident consequences through simulations, establishing individual, plant and social risk factors. MAXCRED is dedicated to consequences estimation, while SCAP is devoted to safety management, and it is applied to define and estimate the effect of risk mitigation means.

Dynamic models have been also developed, like the bow-tie approach proposed by Khazad et al. [12]. Such models are very useful to keep an updated probability estimation for Top Events, in highly dynamic systems.

One of the limitations of such methods lies in a lack of generality in the identification of the mechanics of industrial accidents: since they try to embrace a vast amount of chemical processes, the risk assessment needs to be executed by a highly skilled project team, which must be able to identify the criticalities of the involved issues and translate them in a Fault Tree Analysis.

Historically, a first attempt to integrate an HazOp to FTA method has been the introduction of the Recursive Operability Analysis (ROA), proposed by Piccinini and Ciarambino [13,14]: the main concept consists in working around process variables deviations (following the same pattern of HazOp) but, instead of simply listing them, it interconnects them, based upon a cause-sequence criterion. The method was efficiently used to perform risk assessments in the chemical industry $[15,16]$, and it was also improved. However, ROA presents some flaws: it does not consider that plant state according to protection means working properly, and it can be time expensive, requiring several records even for relatively simple systems [17]. The original ROA has been recently updated, with the implementation of the ROA-Cause Consequence Diagrams (CCD) technique $[17,18]$. This method, 
through a well-structured ROA table (that is very similar to an HazOp analysis), it is possible to deduce a complete fault tree, either including the failure of both automatic and manual protection devices or considering the plant state assuming that protections worked properly. The method is relatively fast to be executed in comparison with the original ROA, as shown in the work of Contini et al. [17]. However, since the ROA-CCD it is still an HazOp-based model, it does not hint which process variable deviations will contribute to accidental Top Events. For these reasons, this paper is devoted to the formulation of a method, with the same structure of the ROA-CCD, that can almost automatically generate and resolve a fault tree, starting from basic process information. Unfortunately, it is unlikely to produce a method applicable to all chemical plants, given the width of potential accidents. The proposed method, which will be referred to as Recursive Operability Analysis Plus with Incidental Sequence Diagrams (ROA Plus-ISD) is a technique dedicated to identify accidental scenarios and their probability estimation, and it is tailored to specifically treat dust explosions. Dust explosions are fatal and severe accidents that affect process industries [19], and methods to carefully establish the risk associated with explosive dust are subject of great interest [20]. When talking about process variables and dust explosions, it is possible to find conjunction in the well-known dust explosion pentagon [21]. According to the pentagon, five conditions have to be simultaneously satisfied in order to make possible a dust explosion: the presence of combustible dust, an oxidizing agent (usually oxygen), dispersion in air, confinement and an ignition source.

The structure of the ROA Plus-ISD consists of defining a priori all process variables, human operations and components involved, moving around the conditions represented by the dust explosion pentagon. Basic events which will be required for the computation of the FTs are deduced by performing an FMEA. Once all the required elements are defined, it is possible to generate the ROA table, where only the deviations related to dust explosion must be considered. Afterward, starting from every single record of the ROA table (that is, a single row), the corresponding ISD can be generated and, by repeating the procedure on all records, the final Fault Trees for the identified Top Events are automatically generated, by matching all the correlated ISDs. Finally, FTA can be performed with dedicated software, such as PROFAT [22], OpenFTA, FaultTree+ [9] or ASTRA [23].

The main difference with respect to ROA-CCD consists in a return to the use of the original Incidental Sequence Diagrams (ISDs) for the generation of fault trees, maintaining the structure of the ROA-CCD table.

This new technique was applied to a case study: the risk assessment of the sugar conveyance line of the former Imperial Sugar plant (Port Wentworth, GA, USA). This site suffered a severe dust explosion throughout the plant in February 2008, and the main cause was the implementation of a closed metal barrier on the conveyor belts, which eventually led to the primary explosion. Risk assessment of this part of the plant has been performed, including the new equipment. The proposed method is able to detect the risk associated with the introduction of a closed barrier, and results are coherent with analyses performed on the same plant with other models [24].

\section{Materials and Methods}

The flowchart of the ROA Plus-ISD is presented in Scheme 1. The procedure can be organized more concisely in the following steps:

- recovering of oxidizing and combustible agents

- classification of the plant in nodes

- collection of components and computation of the FMEA

- collection of human interaction with the system, with possible human errors associated

- identification of process variables and ignition sources for dust explosion

- compile the ROA Plus table

- generate ISDs and the associated FTs

- perform FTA 


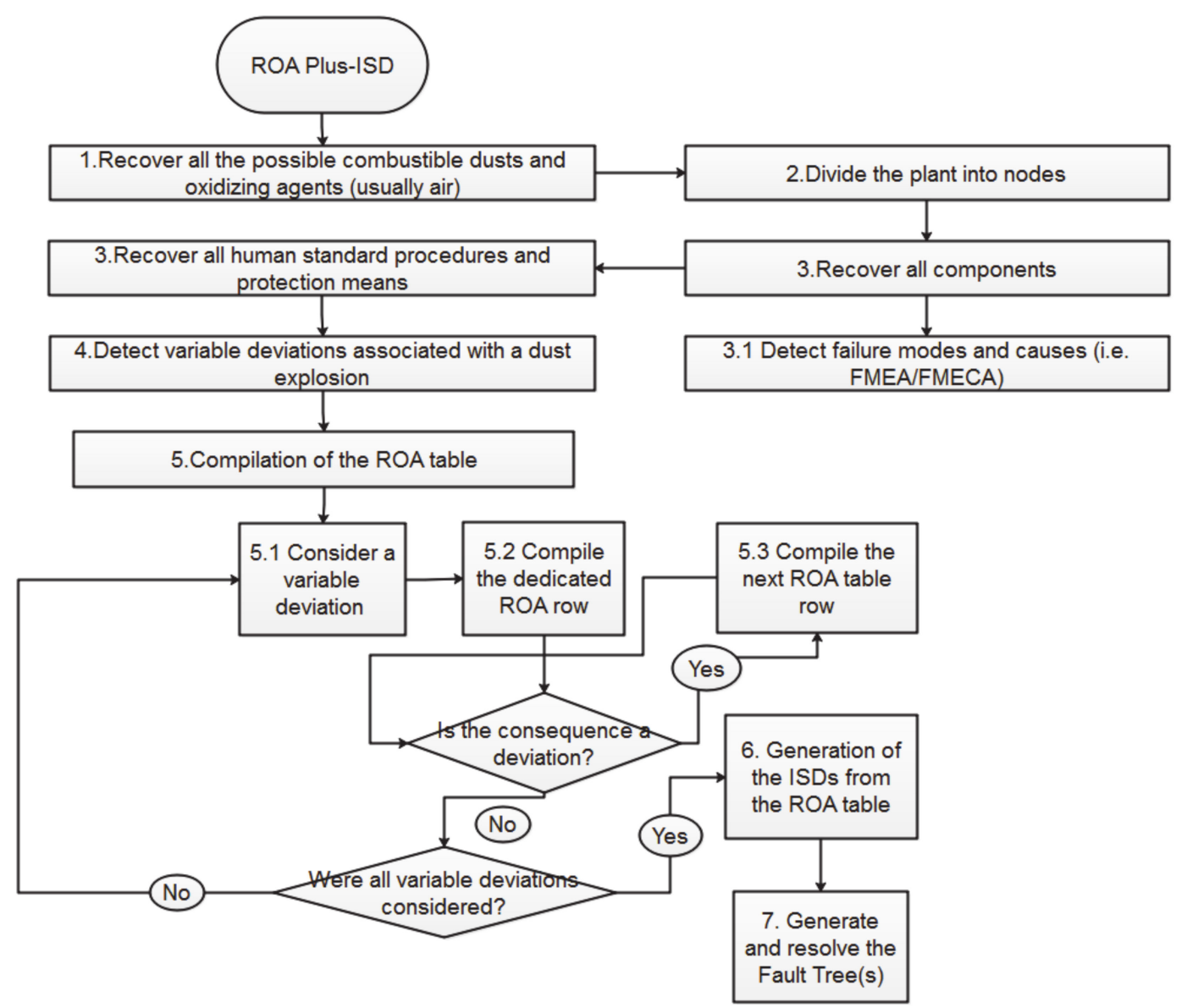

Scheme 1. Flowchart of the ROA Plus-ISD method for dust explosions.

For what concerns the preliminary part of the method, technical details are then reported. The first step consists of listing all the substances present inside the plant, including combustible dusts and oxidizing agents. In this part, it is also crucial to recover all information about dust explosivity, therefore it is necessary to know Minimum Explosive Concentration (MEC), Minimum Ignition Energy (MIE), Limiting Oxygen Concentration (LOC) [25], Minimum Ignition Temperature (MIT) [21], deflagration index $\left(\mathrm{K}_{\mathrm{St}}\right)[26]$.

If certain dust concentrations and/or other characteristic values can be reached inside a plant (in any possible process), then performing a risk analysis concerning dust explosion is necessary. After this, the system should be divided into nodes, possibly distinguishing among different functions of the available equipment. Now, in order to define the basic events that will trigger potential accidents, all components (such as switches, safety systems, elevators, conveyor belts, reactors, valves ... ) must be retrieved and listed (it would be ideal to work with the Piping and Instrumentation Diagram, when available). From this list, failure modes and effects should be defined. In this sense, FMEA/FMECA [5] is a very good tool to accomplish this task, and it is highly suggested for correct implementation of the method. FMEA is performed by completing the scheme reported in Table 1. It is important to notice that failure causes will be the basic events that will appear in the final Fault Trees.

Table 1. Classic FMEA scheme.

\begin{tabular}{|c|c|c|c|c|c|c|c|}
\hline \multirow[b]{2}{*}{ Component } & \multirow[b]{2}{*}{$\begin{array}{l}\text { Description } \\
\text { of the } \\
\text { Function }\end{array}$} & \multirow[b]{2}{*}{$\begin{array}{l}\text { Failure } \\
\text { Modes }\end{array}$} & \multirow[b]{2}{*}{$\begin{array}{l}\text { Failure } \\
\text { Causes }\end{array}$} & \multirow[b]{2}{*}{ Consequences } & \multicolumn{2}{|c|}{ Protections } & \multirow[b]{2}{*}{ Frequencies } \\
\hline & & & & & $\begin{array}{c}\text { Alarms } \\
\text { (Optical/ } \\
\text { Acoustic) }\end{array}$ & $\begin{array}{c}\text { Automatic } \\
\text { Protective } \\
\text { Means }\end{array}$ & \\
\hline
\end{tabular}


Besides, human-based procedures must also be recovered, since they can be crucial for safety issues [27], including both regular ones and protective actions (such as a manual loading or hand valves opening). Human procedures and errors can be treated in an FMEA-like module, indicating for each human interaction with the system the possible errors, which can be also recovered from literature databases $[5,28]$.

The following step consists in defining the process variables involved with dust explosion. Table 2 summarizes these deviations, evinced from the well-known dust explosion pentagon.

Table 2. Process variables related to the explosion pentagon. ( $x$ indicates a generic node, $\mathrm{i}$ indicates the equipment or substance which the variable is referred to; MEC-Minimum Explosive Concentration)

\begin{tabular}{ccc}
\hline Condition & Variable Deviation/s & Symbol \\
\hline \multirow{3}{*}{ Presence of combustible dust } & High concentration $(>\mathrm{MEC})$ & $\mathrm{xhC}_{\mathrm{i}}$ \\
& High mass & $\mathrm{xhm}_{\mathrm{i}}$ \\
& High flow & $\mathrm{xhF}_{\mathrm{i}}$ \\
\hline \multirow{3}{*}{ Presence of oxidizing agent } & High concentration $(>\mathrm{MEC})$ & $\mathrm{xhC}_{\mathrm{i}}$ \\
& High mass & $\mathrm{xhm}_{\mathrm{i}}$ \\
& High flow & $\mathrm{xhF}_{\mathrm{i}}$ \\
\hline \multirow{2}{*}{ Ignition source } & High temperature & $\mathrm{xhT}_{\mathrm{i}}$ \\
& Other sources & - \\
\hline \multirow{2}{*}{ Dispersion } & High concentration $(>\mathrm{MEC})$ & $\mathrm{xhC}_{\mathrm{i}}$ \\
& High temperature & $\mathrm{xhT}_{\mathrm{i}}$ \\
& High pressure & $\mathrm{xhP}_{\mathrm{i}}$ \\
\hline Confinement & Low Volume & $\mathrm{xlV}_{\mathrm{i}}$ \\
\hline
\end{tabular}

It is important to note that these process variables should be also related to specific equipment and substances. The variables reported should be defined in a way so that they can be included in a ROA table so that ISDs can be generated. Figure 1a exhibits the most straightforward Fault Tree to define a dust explosion. However, this structure may have some implications with the application of the ROA Plus-ISD, since it is generally hard to define in terms of process variables a sufficient presence of combustible, oxidizing agent and dispersion. Thus, these three data can be summarized with the variable "concentration". Moreover, a dust explosion can occur when the concentration of dust in the oxidizing agent reaches levels above a precise threshold limit value, which is the Minimum Explosive Concentration [19,21]. In this way, it is possible to represent through process variables the presence of dust inside the explosivity region. Other variables listed in Table 2, such as flow, mass and pressure, are variables that can cooperate to generate airborne dust, but since they are already process variables, the ROA method is already designed to face with these types of interactions. High masses and flow can lead to deposits, which can potentially generate dust clouds. Dispersion in air, can be due to several factors, such as primary explosions, equipment dedicated to dust conveyance and interaction with airflows [21], which are represented by high pressure or high flow. Confinement is usually related to the existence of enclosures in the plant, that is, low volume. While this is a process variable that is definitely not monitored, it is interesting to consider it in case of a new plant parts design. Also, a low available volume often appears as a Boolean variable, indicating whether or not confinement is present inside the facility. Regarding the definition of the ignition source, this issue is also complicated: sources of ignitions are multiple, such as electrical sparks, friction sparks, brush discharges, fires and hot surfaces, which can expose the dust cloud to values greater than the MIT [21]. Unfortunately, most of these are not easily represented by deviations of process variables.For this reason, it is more convenient to consider each ignition source as a cause which should be developed in the ROA table as a variable deviation, in a way that it can be then associated to other process variables or basic failures/events. Hence, all the possible ignition sources should be carefully listed a priori before starting the ROA table compilation. 


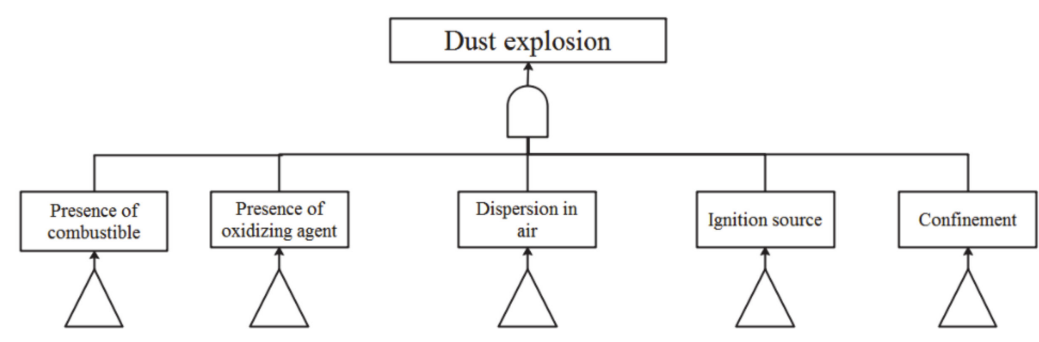

(a)

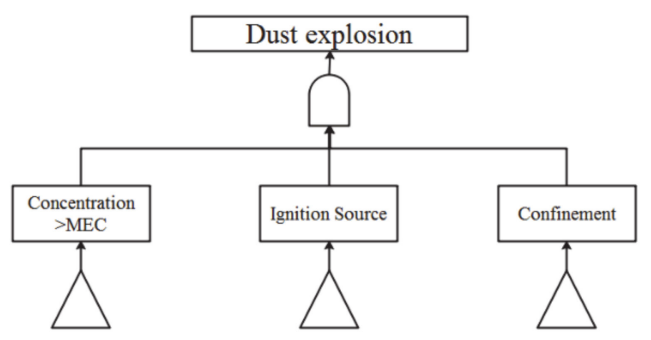

(b)

Figure 1. Dust explosion Fault Trees. (a) The basic structure based on the dust explosion pentagon; (b) The FT structure used for the ROA Plus-ISD.

Once all these preliminary tasks are accomplished, the core part of the method is the execution of the Recursive Operability Analysis (Plus), which consists of the computation of the table represented by the standard format, shown in Table 3. This table is substantially equal to the ROA-CCD table [17,18], which is a more complex version with respect to the classic ROA table $[13,16,29]$. It can be noticed that Column 1 (Node Deviation Variable), basically condenses the 3 elements of the classic HazOp scheme in a single one, including the plant node, the physical variable, and the deviation type. Column 2 represents the causes of the deviation, while Column 3 contains the consequences on the plant (considering the failure of all protective systems). The consequence can be either a modified process variable (such as high pressure following a high temperature) or a Top Event (such as a fire). The table accounts for the presence of eventual protective means, and it separates alarms, which generally require operator intervention and automatic protections. If consequences or causes appear as deviations of additional process variables, the analysis must be carried out until only basic events and Top Events are found.

Table 3. Classic ROA-CCD scheme. (Rec-Record; NDV—Node Deviation Variable; TE—Top Event)

\begin{tabular}{|c|c|c|c|c|c|c|c|c|c|}
\hline \multirow[b]{3}{*}{$\operatorname{Rec}$} & \multirow[b]{3}{*}{ NDV } & \multirow[b]{3}{*}{ Causes } & \multirow{3}{*}{$\begin{array}{l}\text { Consequences } \\
\text { Due to } \\
\text { Protections } \\
\text { Failure }\end{array}$} & \multirow{3}{*}{$\begin{array}{l}\text { Plant state with } \\
\text { Protections } \\
\text { Working } \\
\text { Correctly }\end{array}$} & \multicolumn{3}{|c|}{ Protections } & \multirow[b]{3}{*}{ Notes } & \multirow[b]{3}{*}{ TE } \\
\hline & & & & & \multicolumn{2}{|c|}{ Manual } & \multirow{2}{*}{$\begin{array}{l}\text { Automatic } \\
\text { Safety } \\
\text { Systems } \\
\text { Actions }\end{array}$} & & \\
\hline & & & & & $\begin{array}{c}\text { Alarm } \\
\text { (Optical/ } \\
\text { Acoustic) }\end{array}$ & $\begin{array}{c}\text { Operator } \\
\text { Actions on } \\
\text { Components }\end{array}$ & & & \\
\hline & 1 & 2 & 3 & 4 & 5 & 6 & 7 & & \\
\hline
\end{tabular}

From this point, the main difference between ROA-CCD and this new model come out: according to the ROA-CCD method, after the ROA table is complete, from each record (that is, a row) of the table, a Cause-Consequence-Diagram can be generated, as shown in Scheme 2. It can be noticed that the CCD contains information about the plant state in case of protective means working correctly, allowing for a more proper analysis. However, CCDs can be difficult to be interpreted and connected to generate a Fault Tree. For this reason, it is easier to implement Incidental-Sequence-Diagrams, as shown in Scheme 3 . 


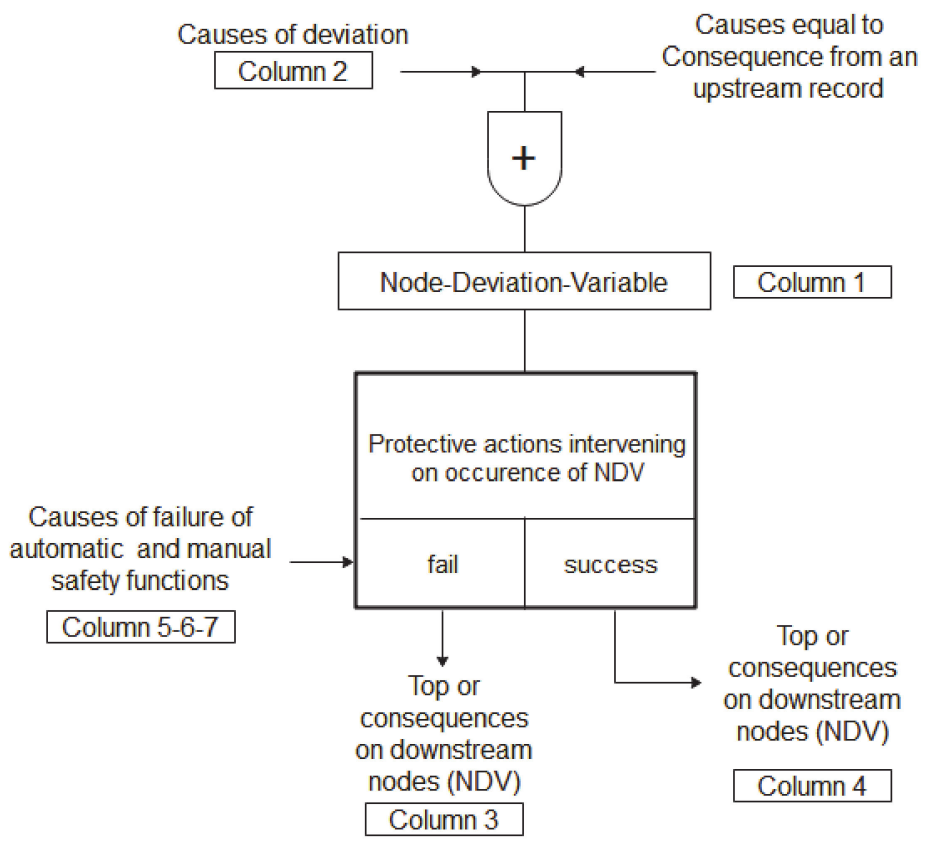

Scheme 2. ISD generation from a ROA-CCD record. (NDV-Node Deviation Variable)

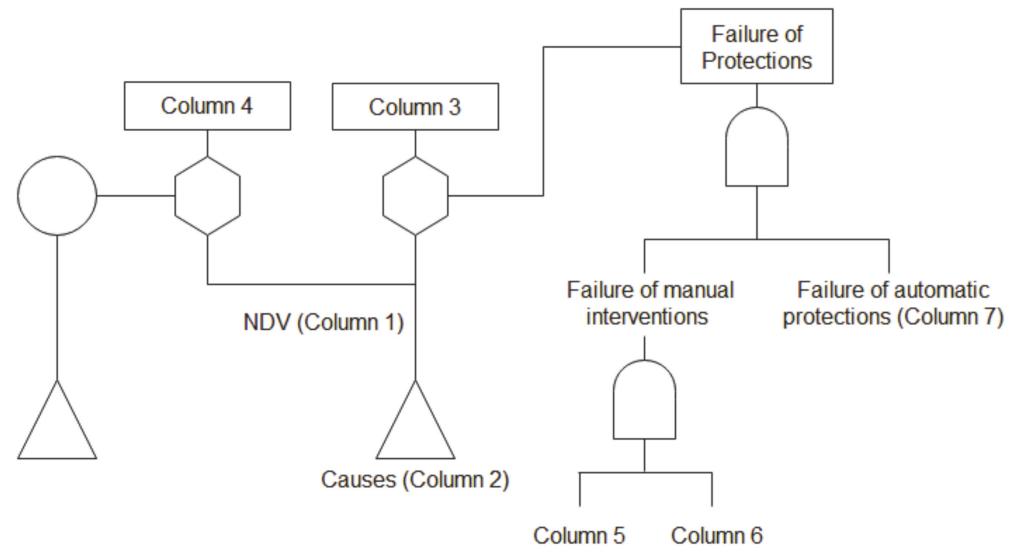

Scheme 3. ISD generation from a ROA Plus-ISD record.

The ISD contains the same information of a CCD, but it is already structured to generate a Fault Tree, allowing for faster generation of Fault Trees. The implementation of Column 4 inside the logic structure acts as a NOT gate: Column 3 represents the state of the plant according to the failure of protections, and column 4 is the state of the plant when protections work correctly (that is, the complementary part). Note that, for simplicity of reading, Column 4 can be eventually removed from the ISD, if the protective means have no impact on the state of the system state.

When all ISDs have been generated, they can be linked together, matching compatible causes and consequences, and a final fault tree hence comes out for each detected top event. For the solution of the fault trees, unavailability/failure rates of a component/human errors are required, which can be eventually retrieved from the literature. The final fault tree can be then solved and analyzed with dedicated software. In this work, OpenFTA 1.0 (Formal Software Construction Ltd., Cardiff, UK) was used.

\subsection{Case Study}

The first explosion at the Imperial Sugar manufacturing facility (Port Wentworth, GA, USA) is considered as the case study of this work. On 7 February 2008 a sugar dust explosion occurred at the 
first floor of the packing building, exactly in the enclosed steel belt conveyor under the granulated sugar storage silos. Seconds later, another massive secondary dust explosion propagated through the entire building. The Imperial Sugar factory was a raw cane sugar refinery. The U.S. Chemical Safety and Hazard Investigation Board (CSB) investigated and reconstructed this event, the final report was considered for the recovery of the information about the process and the explosion.

At the Imperial Sugar plant, a system of screw and belt conveyors, and bucket elevators transported granulated sugar from the refinery to three 32-meter-tall sugar storage silos. It was then transported through conveyors and bucket elevators to specialty sugar processing areas and granulated sugar packaging machines. Sugar products were packaged in four-story packing buildings that surrounded the silos or loaded into railcars and tanker trucks in the bulk sugar loading area [30].

As shown in Figure 2, on the first floor of the packing building there were three 12-meter diameter, 32-meter-tall concrete silos where the granular sugar produced in the refinery building was conditioned and stored. Under the silo floor, a belt conveyors tunnel which contains one Aerobelt ${ }^{\circledR}$ conveyor (which discharged the sugar into the west bucket elevator pit), and a steel belt conveyor (which transported granulated sugar from silo $3 \mathrm{~B}$ and $3 \mathrm{C}$ to the packaging production bucket elevator pit located at the east side of the silo 3C) were located. To avoid possible contaminations of the sugar, in 2007 Imperial sugar decided to enclose the belt conveyor under silo 3B and 3C with stainless-steel panels. Less than one year later a dust explosion occurred into the enclosed belt conveyor.

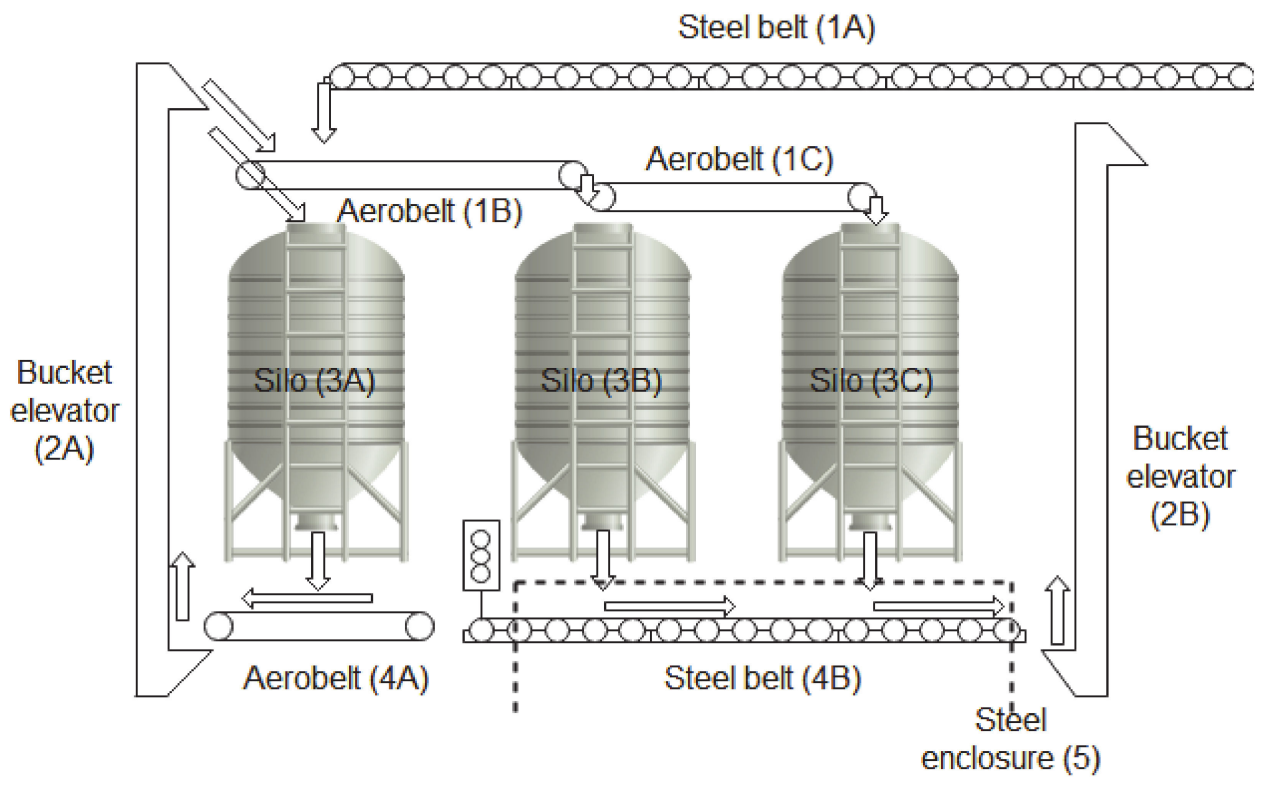

Figure 2. Granulated sugar supply and discharge through the silos. Arrows indicate where sugar flows. In brackets, the dedicated node is indicated.

The surveys carried out by CSB investigators showed that, in addition to the lack of maintenance and housekeeping on the plant, the conveying granulated sugar on the steel belt conveyor generated airborne sugar dust. Also, investigators have discovered, interviewing workers, that sugar lumps often clogged the silo outlet pipe and blocked the movement of the sugar on the belt. As a consequence, the sugar spilling off the belt was released as airborne dust.

The enclosure was not equipped with deflagration vents to reduce safely the overpressure if airborne sugar dust was ignited. Moreover, no dust removal system to prevent the concentration of airborne sugar being exceeded the MEC inside the enclosure was installed to avoid an explosion.

The CSB investigators learned that three days before the explosion, workers were cleaning sugar lumps lodged in the silo 3C. During the cleaning activities, sugar continued to flow on the steel belt conveyor from silo 3B upstream of the silo 3C discharge chutes. The sugar lumps created a sort of dam on the conveyor that caused a sugar spill off the belt. As a result, this leak caused an accumulation of 
spilled sugar inside the covered conveyor and part of the steel belt was covered by the dust. Inside the tunnel sugar dust accumulated above the MEC.

Interviewing the operators, the CSB investigators found that bearing on the steel roller supports sometimes malfunctioned and warmed up, they deduced that the possible source of ignition was a hot bearing inside the enclosed conveyor. The high rise in the temperature of mechanical parts can actually trigger airborne sugar dust, especially if the dust remained in contact with the hot surface for many seconds, as it likely occurs in an unventilated enclosure. Also, if sugar in contact with a hot surface begins to smolder, combustion gases that are released will mix with the airborne sugar dust and decrease the ignition temperature below the ignition temperature of pure sugar dust [21].

\subsection{Application of the ROA Plus-ISD method}

The procedure is applied here step by step.

\subsubsection{Detection of Combustible and Oxidizing Agents}

Sugar dust is the only combustible material present in the facility, oxygen (air) is the oxidizing agent. Explosive properties of sugar dust are reported in Table 4. All the reported values can be reached inside the facility: the MEC can be reached due to lifted dust deposits, air compressor, human-based procedure. The MIT is around $400^{\circ} \mathrm{C}$ : if a sugar deposit catches fire, this temperature can be easily reached. The MIE is fairly high, but that short circuits, electric and friction sparks can release such energies.

Table 4. Explosive properties of samples of granulated sugar collected from the Port Wentworth facility [30].

\begin{tabular}{cc}
\hline Property & Value \\
\hline Minimum Explosive Concentration-MEC & $115 \mathrm{~g} / \mathrm{m}^{3}$ \\
Minimum Ignition Temperature-MIT & $360^{\circ} \mathrm{C}-420^{\circ} \mathrm{C}$ \\
Minimum Ignition Energy-MIE & $>1000 \mathrm{~mJ}$ \\
\hline
\end{tabular}

\subsubsection{Identification of Nodes}

The whole room represented in Figure 2 is the plant section dedicated to sugar dust collection and conveyance. The analysis will include the steel panel used to protect the lower sugar line. The system is divided into five nodes: Node 1A-1B-1C (upper conveyor belts), Node 2A-2B (elevators), Node 3A-3B-3C (silos) and Node 4A-4B-4C (lower conveyor belts), Node 5 (steel enclosure). In particular, among the conveyors both classic roller conveyors and Aerobelt ${ }^{\circledR}$ conveyors are present $(1 \mathrm{~B}-1 \mathrm{C}$ and $4 \mathrm{~A})$. Aerobelt ${ }^{\circledR}$ conveyors exploit air cushions in order to move a powdered material, and they are designed to minimize leaks and dispersions.

\subsubsection{Recovery of Failure Modes and Frequencies from a FMEA}

Components present inside this part of the plant are: switches (Node 4), steel panels (Nodes 1 , 3, 5), conveyor belts (Nodes 1-4), rollers (Nodes 4A, 4B, 4C), fans (for Aerobelt ${ }^{\circledR}$ conveyors 4A, 1B, 1C), discharge valves (Nodes 3A, 3B, 3C). In addition, human operators can access and interact with Nodes 3-4-5. Table 5 reports the FMEA analysis for the involved components. Failure rates were recovered from literature, when available. According to the CSB report [30], some events may be considered unlikely (such as an electric spark from the hand switch. In this case, for the simulation, a conservative value of $1 \times 10^{-6} \mathrm{~h}^{-1}$ was considered. It is known, from plant information, that sugar clogging would occur at the outlet of silos $3 \mathrm{~B}$ and $3 \mathrm{C}$, stopping the sugar conveyance. Whenever this occurred, operators should stop the belt with a dedicated switch, and manually clear the way out with a steel rod. This operation was referred to as "rodding" [30]. In the regular handling of the process, this is the only human intervention foreseen. 
Table 5. FMEA per the involved components and human errors. Frequencies are represented as failure rates. (h-hour; $\mathrm{d} \longrightarrow$ day; $\mathrm{w} \longrightarrow$ week; $\mathrm{y}-\mathrm{year})$

\begin{tabular}{|c|c|c|c|c|c|c|c|}
\hline Component & $\begin{array}{l}\text { Description of the } \\
\text { Function }\end{array}$ & Failure Modes & Failure Causes & Consequences & Protections & Frequencies & Remarks \\
\hline \multirow[b]{2}{*}{ 4B Hand Switch } & \multirow{2}{*}{$\begin{array}{l}\text { Stop of the roller } \\
\text { belt }\end{array}$} & Load arc & $\begin{array}{l}\text { Electric circuit } \\
\text { wearing }\end{array}$ & The load arc can trigger dust deposits ignition & & Unlikely [30] & \\
\hline & & Fails to perform & Switch wearing & $\begin{array}{l}\text { The roller cannot be stopped for maintenance or } \\
\text { emergency purposes }\end{array}$ & & $4 \times 10^{-6} \mathrm{~h}^{-1}[5]$ & \\
\hline \multirow[b]{2}{*}{$\begin{array}{l}\text { 3A-3B-3C (Silos } \\
\text { vessel) }\end{array}$} & \multirow[b]{2}{*}{ Sugar silo } & Release of sugar & Vessel wearing & Sugar released on the ground & & $30 \times 10^{-6} \mathrm{~h}^{-1}[31]$ & \\
\hline & & Flow blocked & Sugar clogging & $\begin{array}{c}\text { Sugar flow is blocked by the clog, requiring human } \\
\text { operator intervention }\end{array}$ & $\begin{array}{l}\text { Operator } \\
\text { intervention } \\
\text { "rodding") }\end{array}$ & $3 w^{-1}[30]$ & \\
\hline \multirow[b]{2}{*}{$\begin{array}{c}\text { 3A-3B-3C } \\
\text { (Discharge valves) }\end{array}$} & \multirow[b]{2}{*}{ Sugar discharge } & Fails to open & Fails to operate & Sugar conveyance cannot start & & $1 \times 10^{-3} \mathrm{~d}^{-1}[31]$ & \\
\hline & & Fails to close & Rupture & $\begin{array}{c}\text { High sugar flow, sugar may accumulate and spread } \\
\text { in the environment }\end{array}$ & & $1 \times 10^{-4} \mathrm{~d}^{-1}[31]$ & \\
\hline \multirow{2}{*}{$\begin{array}{c}\text { 1A-1B-4A } \\
\text { (Aerobelt }{ }^{\circledR} \\
\text { conveyor belts) }\end{array}$} & \multirow{2}{*}{$\begin{array}{l}\text { Conveyance of } \\
\text { sugar }\end{array}$} & Low flow & Belt wearing & $\begin{array}{l}\text { Sugar released inside the air cushion, formation of } \\
\text { ignitable/explosive mixture }\end{array}$ & & $40 \times 10^{-6} \mathrm{~h}^{-1}[5]$ & \\
\hline & & $\begin{array}{l}\text { Fails to start, given } \\
\text { run }\end{array}$ & No air availa-ble & $\begin{array}{l}\text { Sugar conveyance cannot start, sugar accumulates at } \\
\text { the outlet of the silo } 3 \mathrm{~A}\end{array}$ & & $5 \times 10^{-2} y^{-1}[31]$ & \\
\hline \multirow{2}{*}{$\begin{array}{c}\text { 1A-1B-4A } \\
\text { (Aerobelt }{ }^{\circledR} \\
\text { conveyors fans) }\end{array}$} & \multirow{2}{*}{$\begin{array}{l}\text { Conveyance of } \\
\text { sugar }\end{array}$} & High air flow & Wrong voltage & $\begin{array}{l}\text { High sugar flow, sugar may be dispersed and leak } \\
\text { from the belt }\end{array}$ & & $1 \times 10^{-6} \mathrm{~h}^{-1}[31]$ & $\begin{array}{c}\text { Check for } \\
\text { technical details }\end{array}$ \\
\hline & & Low air flow & $\begin{array}{l}\text { Fan wearingORFan } \\
\text { clogged }\end{array}$ & Low sugar flow & & $\begin{array}{l}2 \times 10^{-6} \mathrm{~h}^{-1}[5] 1 \\
\times 10^{-6} \mathrm{~h}^{-1}[31]\end{array}$ & \\
\hline \multirow{3}{*}{$\begin{array}{l}4 \mathrm{~B} \text { (Roller } \\
\text { conveyor belt) }\end{array}$} & \multirow{3}{*}{$\begin{array}{l}\text { Conveyance of } \\
\text { sugar }\end{array}$} & $\begin{array}{l}\text { Fails to start, given } \\
\text { run }\end{array}$ & $\begin{array}{l}\text { Electric circuit } \\
\text { failure }\end{array}$ & $\begin{array}{l}\text { Sugar conveyance cannot start, sugar accumulates at } \\
\text { the outlet of the silo } 3 \mathrm{~B}-3 \mathrm{C}\end{array}$ & & $1 \times 10^{-6} \mathrm{~h}^{-1}[31]$ & \\
\hline & & Overheating & Roller wearing & Overheating can ignite eventual sugar dust deposits & & $5 \times 10^{-6} \mathrm{~h}^{-1}[5]$ & \\
\hline & & Low flow & Belt wearing & $\begin{array}{l}\text { Sugar may spread in the surroundings and } \\
\text { accumulate inside rotating elements }\end{array}$ & & $40 \times 10^{-6} \mathrm{~h}^{-1}[5]$ & \\
\hline \multirow{2}{*}{$\begin{array}{l}\text { 2A-2B (Bucket } \\
\text { elevators) }\end{array}$} & \multirow{2}{*}{$\begin{array}{l}\text { Conveyance of } \\
\text { sugar }\end{array}$} & Low flow & Roller wearing & Sugar conveyance cannot be performed regularly & & $5 \times 10^{-6} \mathrm{~h}^{-1}[5]$ & \\
\hline & & Loose bucket & Bucket wearing & A falling steel bucket may generate a friction spark & & Unlikely [30] & \\
\hline
\end{tabular}


While it is interesting to analyze the impact of this operation on the process (for example, operators may trigger a friction spark with a misuse of the steel rod, the model accounts only for regular protection systems. In this case, possible human errors are listed in Table 6.

Table 6. Human errors involved.

\begin{tabular}{ccc}
\hline Operation & Human Error & Frequency \\
\hline Sugar clogging & Operator omits procedure ("rodding") & $2.00 \times 10^{-3}(-)[28]$ \\
\hline
\end{tabular}

\subsubsection{Indication of the Most Probable Ignition Sources}

Considering the plant, the following have been listed as the most probable ignition sources: electric sparks, friction spark, hot surfaces or a local fire. Electric sparks can be generated by a faulty switch, which is present around the bottom belts line. Friction sparks can be generated by operators, through a bad execution of the "rodding" procedure, or by falling metallic parts. This issue is more critical in the bucket elevators, where buckets can get loose and fall upon other metallic parts. Hot surfaces and fire can be generated through friction between sugar and roller bearings, or by worn roller bearings, if dust deposits are available. This occurs wheter the dust deposit, which acts as a layer, reaches the layer ignition temperature (LIT). Unfortuantely, specific tests to investigate the LIT of the sugar processed in the facility were never performed. According to a Chemwatch Safety Data Sheet for icing sugar, the LIT can be considered to be about $450{ }^{\circ} \mathrm{C}$ [32].

\subsubsection{Process Variables}

All relevant process variables are listed in Table 7. Inside the plant, sugar flows are present in silos 3A-3B-3C, where sugar is sent from silos to the dedicated belts through discharge valves. Sugar flows are also present on buckets elevators $(2 \mathrm{~A}-2 \mathrm{~B})$, and on the conveyor belts $(1 \mathrm{~A}-4 \mathrm{~A}-4 \mathrm{~B})$. Sugar mass indicates deposits, which can occur mainly inside the conveyor belts $4 \mathrm{~A}-4 \mathrm{~B}$, where it can slip through the bearings.

Table 7. Process variables analyzed in the ROA Plus-ISD application.

\begin{tabular}{cc}
\hline Symbol & Process Variable \\
\hline$F$ & Sugar flow \\
$m$ & Sugar mass \\
$C_{a}$ & Airborne sugar dust concentration \\
$T_{m}$ & Temperature of mechanical parts \\
$T_{a}$ & Air temperature \\
$P$ & Pressure \\
$V$ & Volume available \\
\hline
\end{tabular}

Airborn sugar concentration, and air temperature are related to silos $3 \mathrm{~A}-3 \mathrm{~B}-3 \mathrm{C}$, and the enclosure (Node 5). In this case, Nodes $4 \mathrm{~A}-4 \mathrm{~B}$ are very close to Node 5 , since the belts are contained in the enclosure. Pressure is also associated to the dust cloud, which can be present inside all the silos and in the enclosure. The temperature of mechanical parts is referred to generic equipment components, which can act as a hot wall for dust ignition. Volume is strictly referred to confinement, and it is present inside the silos and in the enclosure. Connections among proves variables and nodes are graphically represented in Figure 3. 


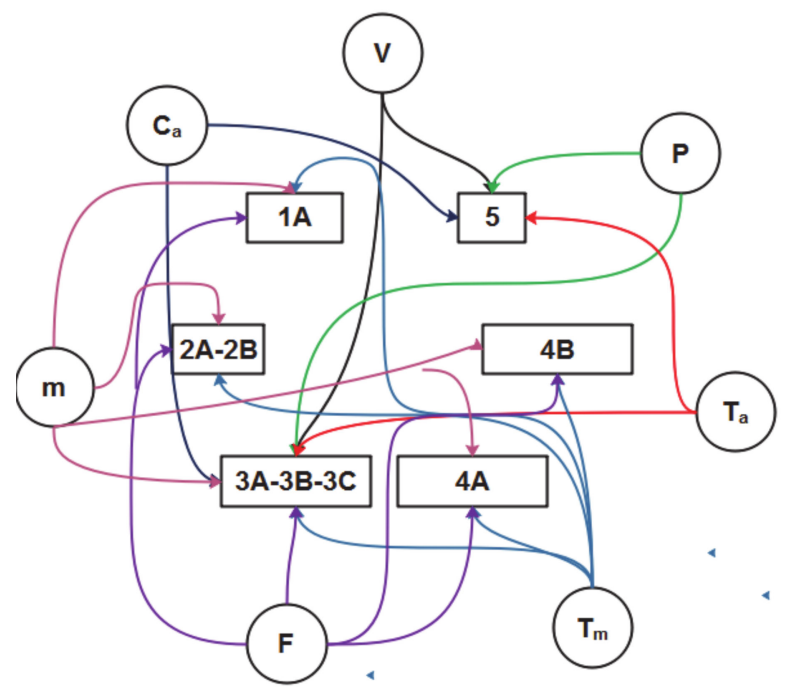

Figure 3. Couplings among process variables (circles), and process nodes (boxes). F-sugar flow; $\mathrm{m}$-sugar mass; $C_{a}$ —airborne sugar dust concentration; $V$-volume available; $P$ —pressure; $T_{a}$ —air temperature; $T_{m}$-temperature of mechanical parts.

\section{Results and Discussion}

ROA Plus-ISD has been applied to the facility involved. In this section, results concerning the steel conveyor belt (Node 4B) and the enclosure (Node 5) are reported. These nodes represent the major criticalities as they represent the zone that witnessed the installation of the steel enclosure, and it is where the primary explosion took place [30].

The ROA table is reported in the Appendix A: Table A1 is the ROA associated with the steel belt (Node 4B), Table A2 represents the analysis on the enclosure (Node 5). In order to make an easier reading of the table, unimportant deviations or redundant elements were omitted. For example, the deviation "low temperature of mechanical parts" is extremely unlikely, and it eventually brings to trivial consequences. Therefore, all deviations experiencing this issue were not then reported.

According to the ROA table, the main deviations associated with a potential sugar dust explosion can be clearly seen: high concentration, air temperature, pressure, confinement, and ignition sources. In this case, sugar dust can become airborne over the regular handling of the process, due to both conveyor belts and sugar flow from the discharge duct from the silos. For this reason, a high concentration of sugar is a direct consequence of having dust deposits. Additional factors that can lift sugar dust in the air are human operations, such as cleaning operations with compressed air, or the "rodding" operation, where an operator is supposed to clear the outlet of sugar after a clogging event. Cleaning operations with compressed air are not normally performed in this part of the plant and the effect of a protection measure (that, is the "rodding" operation after a clogging of the outlet line) is seen in the ROA table.

About the process variables involved, high airborne sugar concentration $h C_{a}$ indicates a concentration above the MEC (Table 4). A high temperature of mechanical parts $h T_{m}$ indicates temperature below LIT but higher than normal temperature, where very high temperature $h h T_{m}$ means temperatures above the LIT, allowing for sugar deposits ignition. Low volume indicates the presence of confinement, which allows for both increasing airborne sugar concentration and pressure accumulation. In this case, confinement is given by the presence of the enclosure. If the enclosure was not present, higher concentrations would be reached only locally, which is inside the silos and in the proximity of sugar deposits and discharge points. While an explosion inside a silo is indeed a critical issue (but it is an object of the analysis dedicated to the specific silo node), for what concerns the $4 \mathrm{~B}$ Node the absence of the enclosure would mean that only local fires are a potential accident, given the lack of confinement. 
As recalled previously, the most important ignition sources were identified as high temperature from a sugar fire, intended as temperature $>$ MIT $\left(h h T_{a}\right)$, electric and friction spark. High temperatures are well represented by regular deviations, while electric and friction spark may not be necessarily basic events, and they must be developed separately. Considering the equipment, an electric spark can be generated by the faulty hand switch, which is highlighted in the FMEA (Table 5). This event was reported as unlikely [30]. For what concerns the overpressure generated, according to literature data, sugar dust exhibits deflagration indexes that can range from 30 to $150 \mathrm{bar} / \mathrm{m} / \mathrm{s}$ [30,33], depending upon the moisture content and particle size distribution. This means that sugar dust explosions can lead to severe damage to both equipment and people. For this reason, it is considered as a level of concern for high pressure, a value equal to $2.76 \mathrm{kPa}$, corresponding to a potential enclosure collapse [31].

From the analysis, four top events have been identified: conveyance of sugar blocked (TE1), sugar spillage (TE2), local fire (TE3), primary explosion (TE4), dust cloud formation (TE5). The blocking of sugar conveyance is due to the sugar clogging, which appears to be a pretty frequent event within the process. In this case, a protective measure is foreseen, that is the "rodding" operations, which require operators to stop the belt motion, and manually clear the sugar outlet. A local fire, on the other hand, can be generated through dust deposits in combination with any ignition source. In particular, dust deposits that fall inside the bearing of the rollers can contribute to dust ignition, compromising their friction. A dust explosion, instead, requires confinement and high dust concentration in combination with a triggering event, which is a local fire or a spark. Also, sugar clogging can determine a visible sugar dust cloud, which is by itself a critical issue that requires attention. From this ROA table, ISDs can be automatically generated.

\subsection{Fault Trees from ISDs}

ISDs can be generated for the top events found. For safety concerns, the most crucial top events are local fire (TE3), formation of a dust cloud (TE4), and the occurrence of a primary dust explosion (TE5). Figures report the complete fault trees, generated by linking all the related ISDs: Figure 4 shows the FT for local fire, Figure 5 shows the FT for dust cloud formation and Figure 6 the FT for a primary dust explosion. For clarity, the event $4 \mathrm{Bhm}$ is shown separately with a transfer gate in Figure 7 . These FTs can be now be analyzed with dedicated software, such as OpenFTA.

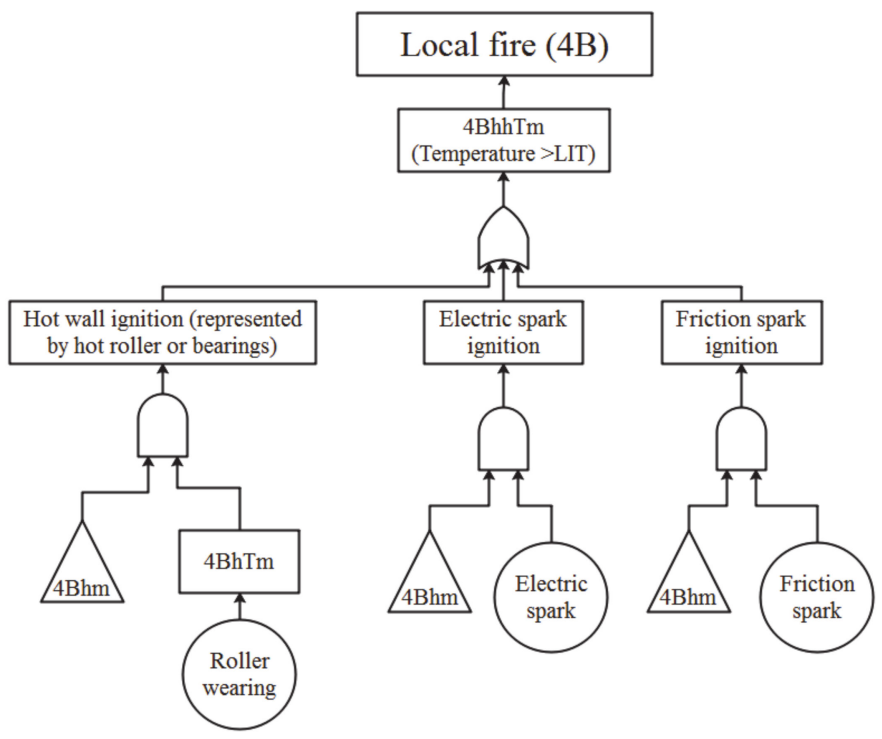

Figure 4. Fault tree for the local fire top event. 4Bhm—high mass inside node 4B; $4 \mathrm{BhTm}$-high temperature of mechanical parts inside node $4 \mathrm{~B}$. 


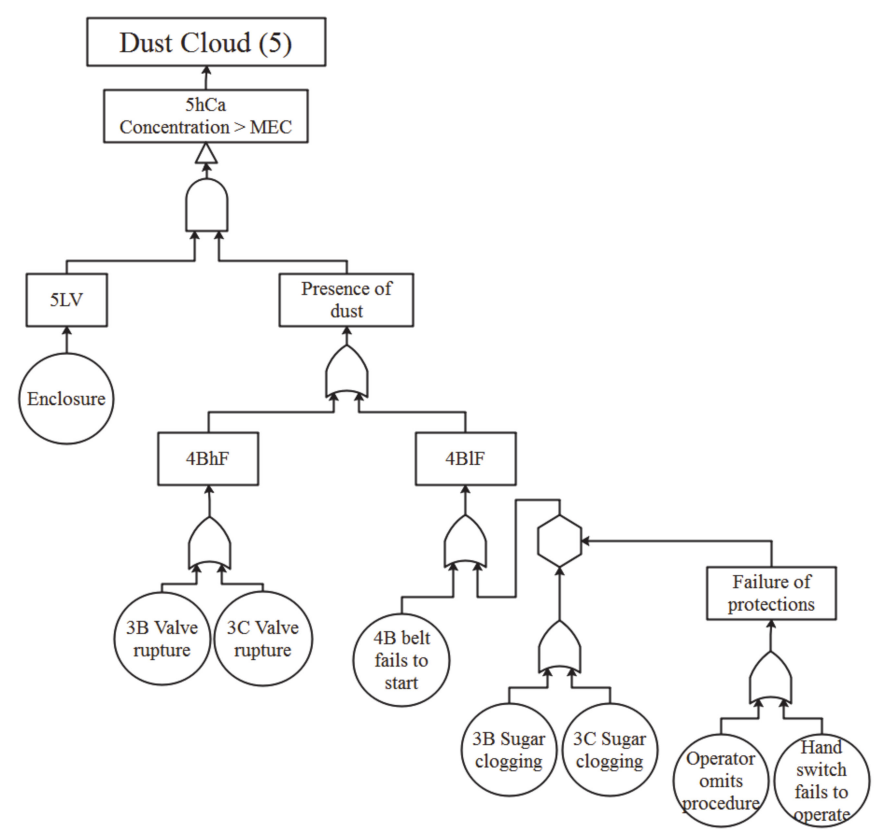

Figure 5. Fault tree for the dust cloud formation top event. 5LV—low volume inside node 5; 4BhF-high sugar flow inside node 4B; $4 \mathrm{BlF}$-low sugar flow inside node $4 \mathrm{~B}$.

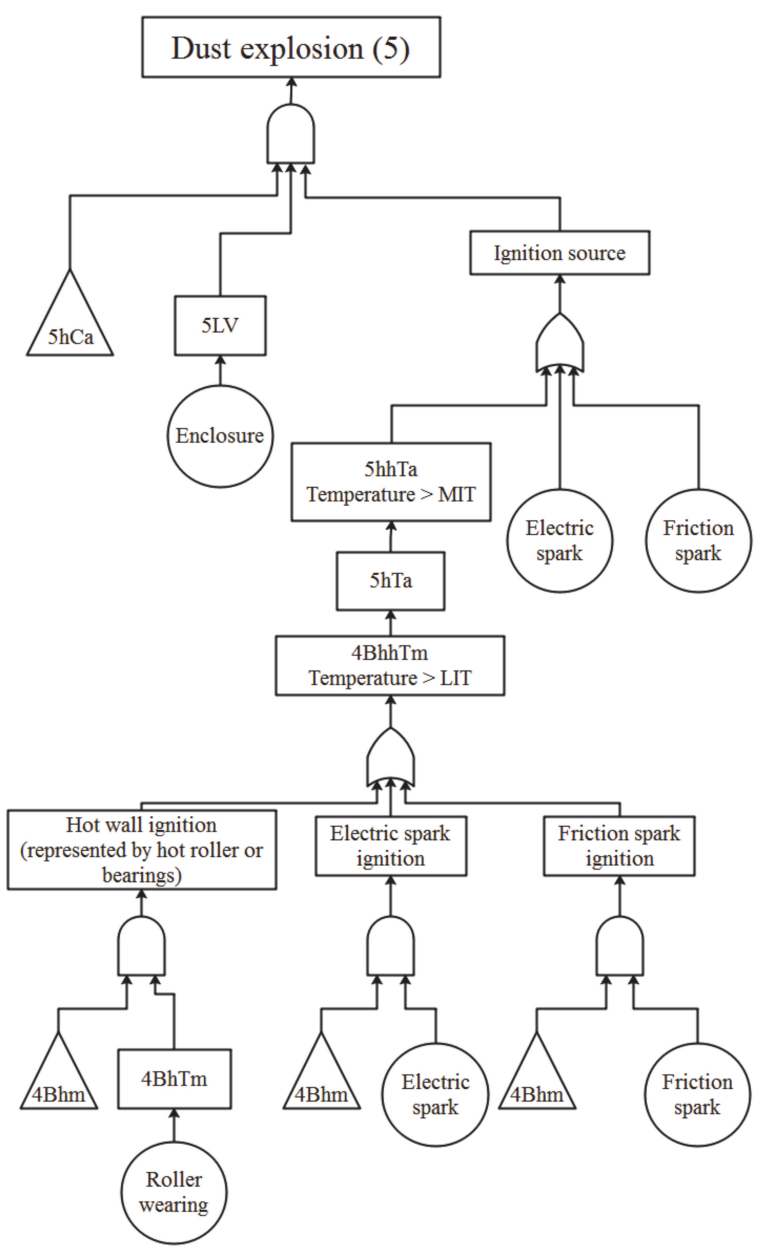

Figure 6. Fault tree for the dust explosion top event. 5hCa-high concentration inside node 5; 5hhTavery high air temperature inside node $5 ; 4 \mathrm{BhhTm}$-very high temperature of mechanical parts inside node 4B. 


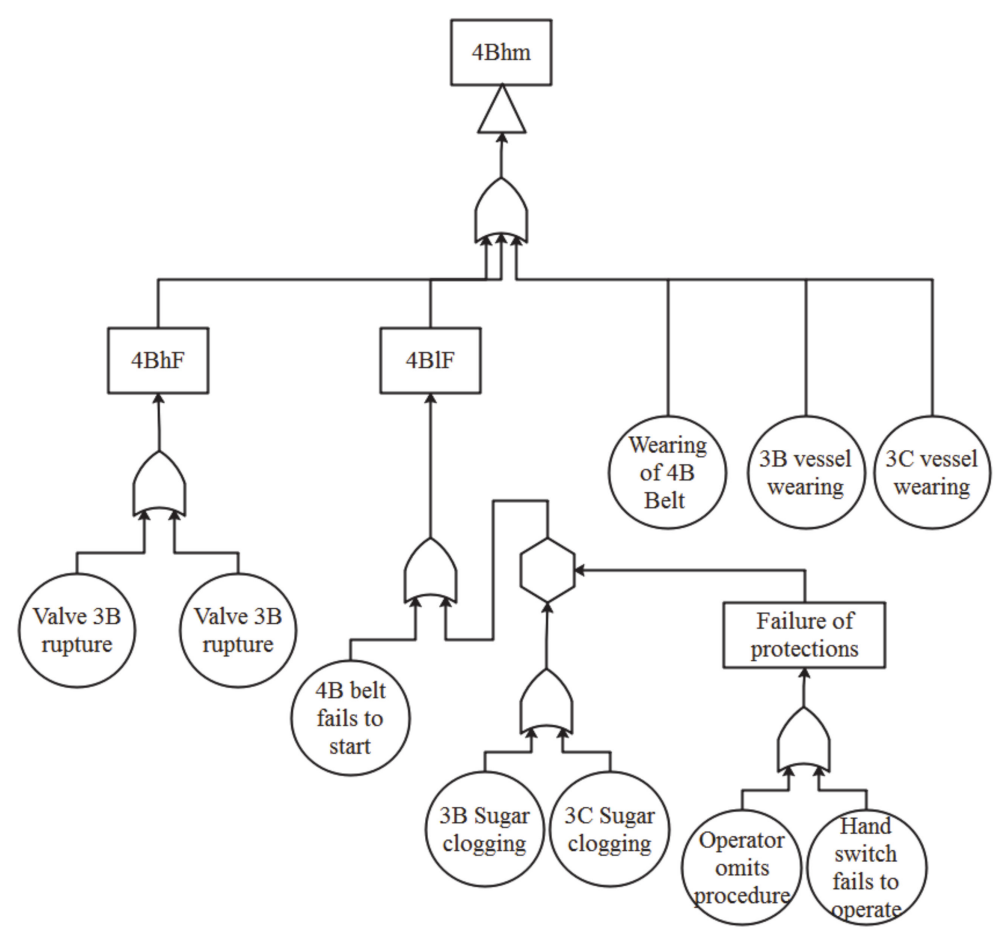

Figure 7. Transfer gate for the $4 \mathrm{Bhm}$ deviation.

Significant process variables, such as concentration and various temperatures have been associated with the critical values they are referred to. It can be noticed in Figures 5 and 7 that the ISDs generated do not include Column 4 of the relative ROA table, which indicates the presence of protections. This part was not included in the graphical representation for simplicity's sake, because when protective actions work correctly (operators performs the standard "rodding" procedure), system goes back to its normal functionality, without severe consequences for the plant state.

\subsection{Fault Tree Analysis}

Fault trees generated have been implemented and analyzed with OpenFTA 1.0. This software performs an FTA and gives as results minimal cut sets, probabilities, and the importance of single basic events. However, in order to have a proper estimation, mission time and unreliability functions must be defined. A mission time of 1 year was considered, this is a reasonable value considering the introduction of a new element in the process (the steel enclosure). Under these circumstances, it is reasonable to consider as negligible, maintenance and repair. Hence, unavailability $P$ of an $i$-th component can be estimated through a Poisson distribution [34], defined in Equation (1):

$$
\mathrm{P}_{\mathrm{i}}(\mathrm{t})=1-\mathrm{e}^{-\lambda \mathrm{t}}
$$

where $t$ is the mission time and $\lambda$ is the failure rate of the component. For human errors, direct probabilities are given from the database. All probabilities for the components listed in the FMEA (Table 5) are shown in Table 8. Short IDs for each failure are also indicated: the first letters indicate the node, and the others the type of basic event. As an example, 5En stands for "enclosure in Node 5". Events considered unlikely have been treated as elements with failure rate equal to $1 \times 10^{-6} \mathrm{~h}^{-1}$, resulting in a probability over one year equal to $8.72 \times 10^{-3}$. The presence of the enclosure acts as a Boolean variable. After its implementation, the associated probability becomes equal to 1 . 
Table 8. Unavailability of components and human errors.

\begin{tabular}{|c|c|c|c|c|c|}
\hline $\begin{array}{l}\text { Component/ } \\
\text { Human Error }\end{array}$ & Failure Mode & Failure Cause & $\begin{array}{l}\text { Failure Rate } \\
\qquad(\lambda)\end{array}$ & $P_{i}(t)$ & ID \\
\hline \multirow{2}{*}{ 4B Hand Switch } & & $\begin{array}{l}\text { Electric circuit } \\
\text { wearing }\end{array}$ & Unlikely [30] & $8.72 \times 10^{-3}$ & HSEl \\
\hline & Fails to perform & Switch wearing & $4.00 \times 10^{-6} \mathrm{~h}^{-1}$ & $3.57 \times 10^{-2}$ & HSW \\
\hline \multirow{2}{*}{ 3A-3B-3C silos } & $\begin{array}{l}\text { Release of } \\
\text { sugar }\end{array}$ & Vessel wearing & $3.00 \times 10^{-5} h^{-1}$ & $2.31 \times 10^{-1}$ & $3 \mathrm{AW}-3 \mathrm{BW}-3 \mathrm{CW}$ \\
\hline & Flow blocked & Sugar clogging & $3.00 \mathrm{w}^{-1}$ & 1.00 & $3 \mathrm{AC}-3 \mathrm{BC}-3 \mathrm{CC}$ \\
\hline \multirow{2}{*}{$\begin{array}{l}\text { 3A-3B-3C Discharge } \\
\text { valves (motor driven) }\end{array}$} & Fails to open & Fails to operate & $1.00 \times 10^{-3} \mathrm{~d}^{-1}$ & $3.06 \times 10^{-1}$ & 3AVO-3BVO-3CVO \\
\hline & Fails to close & Rupture & $1.00 \times 10^{-4} \mathrm{~d}^{-1}$ & $3.58 \times 10^{-2}$ & 3AVR-3BVR-3CVR \\
\hline \multirow{2}{*}{$\begin{array}{c}\text { 1A-1B-4A } \\
\text { (Aerobelt }{ }^{\circledR} \\
\text { conveyor belts) }\end{array}$} & Low flow & Belt wearing & $4.00 \times 10^{-5} \mathrm{~h}^{-1}$ & $2.96 \times 10^{-1}$ & 1ABW-1BBW-4ABW \\
\hline & $\begin{array}{l}\text { Fails to start, } \\
\text { given run }\end{array}$ & No air available & $5.00 \times 10^{-2} \mathrm{y}^{-1}$ & $4.88 \times 10^{-2}$ & 1ABNa-1BBWNa-4ABWNa \\
\hline \multirow{3}{*}{$\begin{array}{c}\text { 1A-1B-4A } \\
\text { (Aerobelt }{ }^{\circledR} \\
\text { conveyor fans) }^{2}\end{array}$} & High air flow & Wrong voltage & $1.00 \times 10^{-6} \mathrm{~h}^{-1}$ & $8.72 \times 10^{-3}$ & 1ABWV-1BBWV-4ABWV \\
\hline & $111 \mathrm{~g}$ a dil now & Fan wearing & $2.00 \times 10^{-6} \mathrm{~h}^{-1}$ & $1.74 \times 10^{-2}$ & 1ABFW-1BFW-4AFW \\
\hline & Low air flow & Fan clogged & $1.00 \times 10^{-6} \mathrm{~h}^{-1}$ & $8.72 \times 10^{-3}$ & 1AFC-1BFC-4AFC \\
\hline \multirow{3}{*}{$\begin{array}{c}4 \mathrm{~B} \\
\text { (Roller conveyor belt) }\end{array}$} & $\begin{array}{l}\text { Fails to start, } \\
\text { given run }\end{array}$ & $\begin{array}{l}\text { Electric circuit } \\
\text { failure }\end{array}$ & $1.00 \times 10^{-6} \mathrm{~h}^{-1}$ & $8.72 \times 10^{-3}$ & 4Bel \\
\hline & Overheating & $\begin{array}{l}\text { Roller bearings } \\
\text { wearing }\end{array}$ & $5.00 \times 10^{-6} \mathrm{~h}^{-1}$ & $4.29 \times 10^{-2}$ & 4BRW \\
\hline & Low flow & Belt wearing & $4.00 \times 10^{-5} \mathrm{~h}^{-1}$ & $2.96 \times 10^{-1}$ & 4BBW \\
\hline \multirow{2}{*}{$\begin{array}{c}\text { 2A-2B (bucket } \\
\text { elevators) }\end{array}$} & Low flow & Roller wearing & $5.00 \times 10^{-6} \mathrm{~h}^{-1}$ & $4.29 \times 10^{-2}$ & 2ARW-2BRW \\
\hline & Loose bucket & Bucket wearing & $1.00 \times 10^{-6} \mathrm{~h}^{-1}$ & $8.72 \times 10^{-3}$ & $2 \mathrm{ABW}-2 \mathrm{ABW}$ \\
\hline "Rodding" & - & $\begin{array}{l}\text { Operator omits } \\
\text { procedure }\end{array}$ & - & $2.00 \times 10^{-3}$ & $\mathrm{HE}$ \\
\hline Friction spark & $\begin{array}{l}\text { Fall of metal } \\
\text { parts }\end{array}$ & - & Unlikely [30] & $8.72 \times 10^{-3}$ & FrS \\
\hline Enclosure & Enclosure & - & - & $1.00-$ & $5 \mathrm{En}$ \\
\hline
\end{tabular}

For the dust cloud event, eight primary events are involved, as shown in Figure 3. Seven minimal cut sets have been identified. Three of the Minimal Cut Sets (MCS) are of second-order, and the others of the third order. For the local fire event, 13 primary events are involved, with 30 minimal cut sets identified. Eighteen of these MCS are of second-order, and the other 12 are third-order MCS. For what concerns dust explosion analysis, 14 primary events are involved, with 21 minimal cut sets identified. Nine of these are MCS of the third-order and the other 12 of fourth-order. All results are summarized in Table 9.

As a general overview, it is well-known that high order MCS and a low number of MCS indicate an intrinsically safe procedure [35]. In this case, a high number of MCS is associated with local fire and dust explosion top events. However, this is highly due to the ROA Plus-ISDs, since it forces the analysis in considering all the possible ignition sources. MCSs are of low order (from 2 to 4), indicating a lack of protective measures. Nevertheless, the most severe event, which is the dust explosion, has the highest MCS orders.

The final estimated probabilities of the top events are the following: $1.13 \times 10^{-1}$ for dust cloud formation, $2.75 \times 10^{-2}$ for local fire and $6.73 \times 10^{-3}$ for dust explosion. This means that a dust cloud is expected to be seen on average every 8.8 years, a local fire every 36 years, and a dust explosion every 148 years. 
Table 9. Probabilities of occurrence P for every MCS identified. (MCS—Minimal Cut Sets)

\begin{tabular}{|c|c|c|c|c|c|c|c|c|}
\hline \multicolumn{3}{|c|}{ Dust Cloud } & \multicolumn{3}{|c|}{ Local Fire } & \multicolumn{3}{|c|}{ Dust Explosion } \\
\hline \# & MCS & $\mathbf{P}(-)$ & \# & MCS & $\mathbf{P}(-)$ & \# & MCS & $\mathbf{P}(-)$ \\
\hline 1 & 3BVR,5En & $3.58 \times 10^{-2}$ & 1 & 3BVR,4BRW & $1.53 \times 10^{-3}$ & 1 & 3BVR,4BRW,5En & $1.53 \times 10^{-3}$ \\
\hline 2 & 3CVR,5En & $3.58 \times 10^{-2}$ & 2 & 3BVR,HSEl & $3.12 \times 10^{-4}$ & 2 & 3BVR,HSEl,5En & $3.12 \times 10^{-4}$ \\
\hline 3 & 4BEl,5En & $8.71 \times 10^{-3}$ & 3 & 3BVR,FrS & $3.12 \times 10^{-4}$ & 3 & 3BVR,FrS,5En & $3.12 \times 10^{-4}$ \\
\hline 4 & 3BC,5En,HSW & $3.57 \times 10^{-2}$ & 4 & 3BW,4BRW & $9.01 \times 10^{-3}$ & 4 & 3CVR,4BRW,5En & $1.53 \times 10^{-3}$ \\
\hline 5 & 3BC,5En,HE & $2.00 \times 10^{-3}$ & 5 & 3BW,HSEl & $1.83 \times 10^{-3}$ & 5 & 3CVR,HSEl,5En & $3.12 \times 10^{-4}$ \\
\hline 6 & 3CC,5En,HSW & $3.57 \times 10^{-2}$ & 6 & 3BW,FrS & $1.83 \times 10^{-3}$ & 6 & 3CVR,FrS,5En & $3.12 \times 10^{-4}$ \\
\hline 7 & 3CC,5En,HE & $2.00 \times 10^{-3}$ & 7 & 3CVR,4BRW & $1.53 \times 10^{-3}$ & 7 & 4BEl,4BRW,5En & $3.74 \times 10^{-4}$ \\
\hline & & & 8 & 3CVR,HSEl & $3.12 \times 10^{-4}$ & 8 & 4BEl,HSEl,5En & $7.60 \times 10^{-5}$ \\
\hline & & & 9 & $3 C V R, F r S$ & $3.12 \times 10^{-4}$ & 9 & 4BEl,FrS,5En & $7.60 \times 10^{-5}$ \\
\hline & & & 10 & $3 \mathrm{CW}, 4 \mathrm{BRW}$ & $9.01 \times 10^{-3}$ & 10 & 3BC,4BRW,5En,HSW & $1.53 \times 10^{-3}$ \\
\hline & & & 11 & 3CW,HSEl & $1.83 \times 10^{-3}$ & 11 & $3 \mathrm{BC}, 4 \mathrm{BRW}, 5 \mathrm{En}, \mathrm{HE}$ & $8.56 \times 10^{-5}$ \\
\hline & & & 12 & 3CW,FrS & $1.83 \times 10^{-3}$ & 12 & 3BC,HSEl,5En,HSW & $3.11 \times 10^{-4}$ \\
\hline & & & 13 & 4BBW,4BRW & $1.27 \times 10^{-3}$ & 13 & 3BC,HSEl,5En,HE & $1.74 \times 10^{-5}$ \\
\hline & & & 14 & 4BRW,4BEl & $3.74 \times 10^{-4}$ & 14 & 3BC,FrS,5En,HSW & $3.11 \times 10^{-4}$ \\
\hline & & & 15 & 4BBW,HSEl & $2.58 \times 10^{-4}$ & 15 & 3BC,FrS,5En,HE & $1.74 \times 10^{-5}$ \\
\hline & & & 16 & 4BBW,FrS & $2.58 \times 10^{-4}$ & 16 & 3CC,4BRW,5En,HSW & $1.53 \times 10^{-3}$ \\
\hline & & & 17 & 4BEl,HSEl & $7.60 \times 10^{-5}$ & 17 & 3CC,4BRW,5En,HE & $8.56 \times 10^{-5}$ \\
\hline & & & 18 & 4BEl,FrS & $7.60 \times 10^{-5}$ & 18 & 3CC,HSEl,5En,HSW & $3.11 \times 10^{-4}$ \\
\hline & & & 19 & 3BC,4BRW,HSW & $1.53 \times 10^{-3}$ & 19 & 3CC,HSEl,5En,HE & $1.74 \times 10^{-5}$ \\
\hline & & & 20 & 3BC,4BRW,HE & $8.57 \times 10^{-5}$ & 20 & 3CC,FrS,5En,HSW & $3.11 \times 10^{-4}$ \\
\hline & & & 21 & 3BC,HSEl,HSW & $3.12 \times 10^{-4}$ & 21 & $3 \mathrm{CC}, \mathrm{FrS}, 5 \mathrm{En}, \mathrm{HE}$ & $1.74 \times 10^{-5}$ \\
\hline & & & 22 & 3BC,HSEl,HE & $1.74 \times 10^{-5}$ & & & \\
\hline & & & 23 & 3BC,FrS,HSW & $3.12 \times 10^{-4}$ & & & \\
\hline & & & 24 & 3BC,FrS,HE & $1.74 \times 10^{-5}$ & & & \\
\hline & & & 25 & 3CC,4BRW,HSW & $1.53 \times 10^{-3}$ & & & \\
\hline & & & 26 & 3CC,4BRW,HE & $8.57 \times 10^{-5}$ & & & \\
\hline & & & 27 & 3CC,HSEl,HSW & $3.12 \times 10^{-4}$ & & & \\
\hline & & & 28 & 3CC,HSEl,HE & $1.74 \times 10^{-5}$ & & & \\
\hline & & & 29 & 3CC,FrS,HSW & $3.12 \times 10^{-4}$ & & & \\
\hline & & & 30 & 3CC,FrS,HE & $1.74 \times 10^{-5}$ & & & \\
\hline
\end{tabular}

These results are consistent: it is reasonable to have an order of magnitude between dust cloud formation and local fire, and between local fire and dust explosion. According to such results, the generation of a dust cloud appears to be a pretty frequent event. This finds evidence in the accident reconstruction, as sugar was spread in the whole facility [30]. The most important factors that contribute to the formation of a dust cloud are the presence of the enclosure (100\% importance, it is present in each MCS), and the hand switch failure in case of sugar clogging (63.19\% importance). The least impactful events are the omission of procedure from the operator ( $3.53 \%$ importance), and the failure to start of the $4 \mathrm{~B}$ belt $(7.70 \%$ importance). For what concerns a local fire accident, the most important event is the wearing of the bearing of the $4 \mathrm{~B}$ belt $(94.27 \%$ importance). This fact is extremely interesting since it finds significant evidence in the accident analysis: operators reported that bearings would heat very often over their process phase [30]. The least impactful primary events are still the omission of procedure from the operator ( $0.88 \%$ importance), and the failure to start of the $4 \mathrm{~B}$ belt $(1.91 \%$ importance). For dust explosion, the presence of the enclosure has still 100\% importance, since it is the only cause of confinement inside this node. Bearings wearing is still the most probable ignition source (99.24\% importance). Such values are unacceptable in accordance with the ALARP principle [36]. These results have been compared with another risk assessment, performed on the same plant by Abuswer et al. [24]. In their work, they estimated a probability of occurrence of a dust explosion including a correction factor to estimated probabilities, based on the consequences of an eventual explosion. According to their simulation, the probability changed from $3.76 \times 10^{-2}$ to $4.4 \times 10^{-5}$ [24], after the application of the corrective factor. The result of this work brings to an intermediate value, being equal to $6.73 \times 10^{-3}$, and it is very close to the result obtained by not including the QRMF correction. This work does not discuss the estimation of the magnitude of the events, nevertheless, events such as fires and explosions generate individual risk indexes which are different from the probabilities alone. In this sense, local fires and dust explosions with probabilities of occurrence equal 
to $2.75 \times 10^{-2}$ and $6.73 \times 10^{-3}$ over one year, respectively, will not generate individual risk levels lower than $1.0 \times 10^{-3}$, which is the lower bound for the ALARP region. This analysis highlights the importance of considering the effect of plant changes, such as the addition of an enclosure on conveyor belts, by performing a proper risk assessment.

\section{Conclusions}

In this work, a method to generate fault trees specifically tailored for dust explosions has been developed and applied. The method consists of applying an enhanced version of the recursive operability analysis, called ROA Plus-ISD, as described in this paper. The aim of the work is to propose a highly structured procedure which can be implemented by a wide range of users, even without a deep knowledge of the topic. The method is based upon a structured information recovery in the preliminary part. Required information cover both technical characteristics, such as $\mathrm{K}_{\mathrm{St}}$ and MIE, and plant information, as components and human-based procedures. These should be analyzed with a tool such as a FMEA, in order to define failure modes and causes, which will be the basic events of the final fault tree. After this preliminary work, the ROA Plus-ISD table can be completed, by analyzing each deviation formerly identified. Once the ROA Plus table is compiled, ISDs and FTs can be automatically generated. The whole procedure is almost automatic but analyst skills are always necessary for the generation of the ROA table. Nevertheless, some limitations of the model can be pointed out: while the model proposed is an attempt of making a highly automatized risk assessment tool, the method is very sensitive with respect to the preliminary part, which still requires a good knowledge of the process plant and physical phenomena involved. Especially in complex plants, all components must be carefully recovered and listed, or results would be otherwise unreliable. Also, ignition sources and human interactions may be complicated to be identified, and they should be thoroughly investigated and discussed.

The procedure was used to perform the risk assessment of the Imperial Sugar Plant, focussing on the sugar conveyor line, a plant zone that witnessed a severe accident after the installation of a steel enclosure. From the results, it is highlighted the strong effect of the presence of an enclosure on the occurrence of serious accidents. Numerical probabilities and comments are in accordance with the reconstruction, providing unacceptable risk for each safety issue noticed. This suggests that if a simple but detailed analysis (such as a ROA Plus-ISD) of the risk associated to the plant had been carried out before making operative the plant itself, the catastrophic combustible dust explosion occurred at Imperial Sugar could have been avoided.

Author Contributions: M.B., S.C., M.S.S. and V.T. conceived the presented work. V.T. provided literature information to define the context. S.C. provided the technical characteristics of the case study. M.B. wrote the manuscript with support from S.C., M.S.S. and V.T.; S.C. and M.S.S. carried out the ROA Plus-ISD analysis. M.B performed the calculations with OpenFTA 1.0 software. M.S.S checked the vailidity of numerical results. S.C. and V.T. analyzed and commented the results. All authors have read and agreed to the published version of the manuscript.

Funding: This research received no external funding.

Conflicts of Interest: The authors declare no conflicts of interest. 


\section{Appendix A}

Table A1. ROA for the enclosed steel belt conveyor (Node 4B).

\begin{tabular}{|c|c|c|c|c|c|c|c|c|c|}
\hline \multirow[b]{3}{*}{$\operatorname{Rec}$} & \multirow[b]{3}{*}{ NDV } & \multirow[b]{3}{*}{ Causes } & \multirow{3}{*}{$\begin{array}{l}\text { Consequences Due } \\
\text { to Protections } \\
\text { Failure }\end{array}$} & \multirow{3}{*}{$\begin{array}{l}\text { Plant State with } \\
\text { Protections } \\
\text { Working Correctly }\end{array}$} & \multicolumn{3}{|c|}{ Protections } & \multirow[b]{3}{*}{ Notes } & \multirow[b]{3}{*}{ TE } \\
\hline & & & & & \multicolumn{2}{|c|}{ Manual } & \multirow[b]{2}{*}{$\begin{array}{l}\text { Automatic Safety } \\
\text { Systems Actions }\end{array}$} & & \\
\hline & & & & & $\begin{array}{l}\text { Alarm (Optical/ } \\
\text { Acoustic) }\end{array}$ & $\begin{array}{c}\text { Operator } \\
\text { Actions on } \\
\text { Components }\end{array}$ & & & \\
\hline 4.1 & $4 \mathrm{BhF}$ & $\begin{array}{c}\text { Discharge Valve 3B } \\
\text { Rupture; OR } \\
\text { Discharge Valve 3C } \\
\text { Rupture } \\
\end{array}$ & $4 \mathrm{Bhm}$ & & - & - & - & $\begin{array}{l}\text { In case of a worn } 4 \mathrm{~B} \text { belt } \\
\text { sugar may slide into } \\
\text { bearings }\end{array}$ & \\
\hline 4.2 & $4 \mathrm{BlF}$ & $\begin{array}{c}\text { Sugar clogging 3B; OR } \\
\text { Sugar clogging } 3 \mathrm{C} ; \mathrm{OR} 4 \mathrm{~B} \\
\text { Belt fails to start (electrical } \\
\text { circuit failure) }\end{array}$ & $\begin{array}{c}\text { 5hCa (due to Sugar } \\
\text { transportation } \\
\text { blocked) } \\
4 \mathrm{Bhm}\end{array}$ & $\begin{array}{l}\text { System goes back to } \\
\text { normal } \\
\text { functionality }\end{array}$ & - & $\begin{array}{l}\text { Belt Switch Off } \\
\text { AND } \\
\text { "Rodding" } \\
\text { operation- }\end{array}$ & & $\begin{array}{l}\text { Provide operational } \\
\text { procedures for cleaning } \\
\text { lumps }\end{array}$ & TE1 \\
\hline 4.3 & $4 \mathrm{Bhm}$ & $\begin{array}{c}\text { 4BhF; OR 4BlF; OR } \\
\text { Wearing of 4B Belt; OR 3B } \\
\text { vessel wearing; OR 3C } \\
\text { vessel wearing }\end{array}$ & Sugar spillage & & - & - & - & $\begin{array}{l}\text { Sugar may slide into } \\
\text { bearings, increasing their } \\
\text { temperature and lowering } \\
\text { their service life }\end{array}$ & TE2 \\
\hline 4.4 & $4 \mathrm{BhTm}$ & Roller bearings wearing & 4BhhTm & & - & - & - & $\begin{array}{c}\text { Bearings reach a } \\
\text { temperature }>\text { LIT }\end{array}$ & \\
\hline 4.5 & 4BhhTm & $\begin{array}{c}\text { 4Bhm; AND (4BhTm; OR } \\
\text { Friction spark; OR Electric } \\
\text { spark) }\end{array}$ & $\begin{array}{c}\text { 5hTa (dust can be } \\
\text { ignited by a hot } \\
\text { spot or by a spark) } \\
\text { Local fire }\end{array}$ & & & & & $\begin{array}{l}\text { Install temperature sensor } \\
\text { inside the enclosure close } \\
\text { to the rollers }\end{array}$ & TE3 \\
\hline
\end{tabular}

Rec—Record; TE—Top Event; h—high; hh—very high; l—low; T—-temperature; P—pressure; C—concentration; F-flow. 
Table A2. ROA for the enclosure (Node 5).

\begin{tabular}{|c|c|c|c|c|c|c|c|c|c|}
\hline \multirow[b]{3}{*}{ Rec } & \multirow[b]{3}{*}{ NDV } & \multirow[b]{3}{*}{ Causes } & \multirow{3}{*}{$\begin{array}{c}\text { Consequences } \\
\text { Due to } \\
\text { Protections } \\
\text { Failure }\end{array}$} & \multirow{3}{*}{$\begin{array}{l}\text { Plant State with } \\
\text { Protections } \\
\text { Working Correctly }\end{array}$} & \multicolumn{3}{|c|}{ Protections } & \multirow[b]{3}{*}{ Notes } & \multirow[b]{3}{*}{ TE } \\
\hline & & & & & \multicolumn{2}{|c|}{ Manual } & \multirow{2}{*}{$\begin{array}{l}\text { Automatic } \\
\text { Safety Systems } \\
\text { Actions }\end{array}$} & & \\
\hline & & & & & $\begin{array}{c}\text { Alarm } \\
\text { (Optical/Acoustic) }\end{array}$ & $\begin{array}{c}\text { Operator } \\
\text { Actions on } \\
\text { Components }\end{array}$ & & & \\
\hline 5.1 & $5 \mathrm{hTa}$ & 4BhhTm & 5hhTA & & & & & $\begin{array}{c}\text { Combustion of sugar deposits triggers } \\
\text { Temperature may reach values } \\
\text { >MIT }\end{array}$ & \\
\hline 5.2 & $5 \mathrm{hCa}$ & (4BlF; OR 4BhF); AND 5LV & Sugar dust cloud & & - & - & & $\begin{array}{l}\text { Require checking from operators, } \\
\text { install dust collecting system }\end{array}$ & TE4 \\
\hline
\end{tabular}




\section{References}

1. Amin, M.T.; Khan, F.; Amyotte, P. A bibliometric review of process safety and risk analysis. Process Saf. Environ. Prot. 2019, 126, 366-381. [CrossRef]

2. Mkpat, E.; Reniers, G.; Cozzani, V. Process safety education: A literature review. J. Loss Prev. Process Ind. 2018, 54, 18-27. [CrossRef]

3. Casal, J. Chapter 11-Quantitative Risk Analysis. In Evaluation of the Effects and Consequences of Major Accidents in Industrial Plants, 2nd ed.; Casal, J., Ed.; Elsevier B.V.: Amsterdam, The Netherlands, 2018; pp. 439-481.

4. Goerlandt, F.; Khakzad, N.; Reniers, G. Validity and validation of safety-related quantitative risk analysis: A review. Risk Anal. Valid. Trust Risk Manag. 2017, 99, 127-139. [CrossRef]

5. Smith, D.J. Reliability, Maintainability and Risk: Practical Methods for Engineers; Butterworth-Heinemann: Oxford, UK, 2017.

6. Kletz, T.A. Hazop and Hazan: Identifying and Assessing Process Industry Hazards; IChemE: London, UK, 2001.

7. Liu, H.-C. Improved FMEA Methods for Proactive Healthcare Risk Analysis; Springer: Singapore, 2019.

8. Kritzinger, D. 4-Fault tree analysis. In Aircraft System Safety; Kritzinger, D., Ed.; Woodhead Publishing: Cambridge, UK, 2017; pp. 59-99.

9. Ruijters, E.; Stoelinga, M. Fault tree analysis: A survey of the state-of-the-art in modeling, analysis and tools. Comput. Sci. Rev. 2015, 15-16, 29-62. [CrossRef]

10. Khan, F.I.; Abbasi, S.A. MAXCRED—A new software package for rapid risk assessment in chemical process industries. Environ. Model. Softw. 1998, 14, 11-25. [CrossRef]

11. Khan, F.I.; Iqbal, A.; Ramesh, N.; Abbasi, S.A. SCAP: A new methodology for safety management based on feedback from credible accident-probabilistic fault tree analysis system. J. Hazard. Mater. 2001, 87, $23-56$. [CrossRef]

12. Khakzad, N.; Khan, F.; Amyotte, P. Dynamic risk analysis using bow-tie approach. Reliab. Eng. Syst. Saf. 2012, 104, 36-44. [CrossRef]

13. Piccinini, N.; Ciarambino, I. Operability analysis devoted to the development of logic trees. Reliab. Eng. Syst. Saf. 1997, 55, 227-241. [CrossRef]

14. Piccinini, N.; Scarrone, M.; Ciarambino, I. Probabilistic analysis of transient events by an event tree directly extracted from operability analysis: Evaluation of accidental releases of gas from a pressure-regulating installation. J. Loss Prev. Process Ind. 1994, 7, 23-32. [CrossRef]

15. Arena, U.; Romeo, E.; Mastellone, M.L. Recursive Operability Analysis of a pilot plant gasifier. J. Loss Prev. Process Ind. 2008, 21, 50-65. [CrossRef]

16. Demichela, M.; Marmo, L.; Piccinini, N. Recursive operability analysis of a complex plant with multiple protection devices. Reliab. Eng. Syst. Saf. 2002, 77, 301-308. [CrossRef]

17. Contini, S.; Contini, P.M.; Torretta, V.; Cattaneo, C.S.; Raboni, M.; Copelli, S. Comparison of classical and 'cause consequence diagrams' Recursive Operability Analysis: The T2 Laboratories accident. Chem. Eng. Trans. 2016, 53, 109-114. [CrossRef]

18. Contini, P.M.; Contini, S.; Copelli, S.; Rota, R.; Demichela, M. From HazOp study to automatic construction of cause consequence diagrams for frequency calculation of hazardous plant states. In Safety and Reliability of Complex Engineered Systems_-Proceedings of the 25th European Safety and Reliability Conference, ESREL 2015; CRC Press: Boca Raton, FL, USA, 2015; pp. 347-355.

19. Amyotte, P. An Introduction to Dust Explosions; Butterworth-Heinemann: Boston, MA, USA, 2013.

20. Davis, S.; Hinze, P.; Hansen, O.; van Wingerden, K. Does your facility have a dust problem: Methods for evaluating dust explosion hazards. J. Loss Prev. Process Ind. 2011, 24, 837-846. [CrossRef]

21. Eckhoff, R.K. Dust Explosions in the Process Industries; Elsevier B.V.: Amsterdam, The Netherlands, 2003.

22. Khan, F.I.; Abbasi, S.A. PROFAT: A user friendly system for probabilistic fault tree analysis. Process Saf. Prog. 1999, 18, 42-49. [CrossRef]

23. Matuzas, V.; Contini, S. European Commission, Joint Research Centre, and Institute for the Protection and the Security of the Citizen. ASTRA Plus User Manual: Description of How to Use the Modules for Fault Tree Analysis and Concurrent Importance and Sensitivity Analysis; Publications Office: Luxembourg, 2012.

24. Abuswer, M.; Amyotte, P.; Khan, F. A quantitative risk management framework for dust and hybrid mixture explosions. J. Loss Prev. Process Ind. 2013, 26. [CrossRef] 
25. Eckhoff, R.K. Measurement of minimum ignition energies (MIEs) of dust clouds-History, present, future. J. Loss Prev. Process Ind. 2019, 61, 147-159. [CrossRef]

26. Fumagalli, A.; Derudi, M.; Rota, R.; Copelli, S. Estimation of the deflagration index KSt for dust explosions: A review. J. Loss Prev. Process Ind. 2016, 44, 311-322. [CrossRef]

27. Kletz, T.; Amyotte, P. Chapter 7-Accidents said to be due to human error. In What Went Wrong? 6th ed.; Kletz, T., Amyotte, P., Eds.; Butterworth-Heinemann: Boston, MA, USA, 2019; pp. 153-172.

28. Bello, G.C.; Colombari, V. The human factors in risk analyses of process plants: The control room operator model 'TESEO'. Reliab. Eng. 1980, 1, 3-14. [CrossRef]

29. Marmo, L.; Crivelletto, V.; Starace, A. Recursive Operability Analysis as a decision support tool for Risk-Based Maintenance. J. Loss Prev. Process Ind. 2009, 22, 557-565. [CrossRef]

30. Imperial Sugar Company Dust Explosion and Fire |CSB. Available online: https://www.csb.gov/imperialsugar-company-dust-explosion-and-fire/ (accessed on 5 November 2019).

31. Lees, F. Lees' Loss Prevention in the Process Industries: Hazard Identification, Assessment and Control; Elsevier B.V.: Amsterdam, The Netherlands, 2005.

32. Bundaber Sugar Ltd. Bundaberg Icing Sugar MSDS No. 4.1.1.1. 11 June 2012. Available online: https: //www.bundysugar.com.au/files/MSDS\%20Icing\%20Mixture_0.pdf (accessed on 10 April 2020).

33. Copelli, S.; Barozzi, M.; Scotton, M.S.; Fumagalli, A.; Derudi, M.; Rota, R. A predictive model for the estimation of the deflagration index of organic dusts. Process Saf. Environ. Prot. 2019, 126, 329-338. [CrossRef]

34. Crowl, D.A.; Louvar, J.F. Chemical Process Safety: Fundamentals with Applications, 2nd ed.; Prentice Hall PTR: Upper Saddle River, NJ, USA, 2002.

35. Kececioglu, D. Reliability Engineering Handbook, 1st ed.; Prentice Hall: Englewood Cliffs, NJ, USA, 1991.

36. Jones-Lee, M.; Aven, T. ALARP—What does it really mean? Reliab. Eng. Syst. Saf. 2011, 96, 877-882. [CrossRef]

(C) 2020 by the authors. Licensee MDPI, Basel, Switzerland. This article is an open access article distributed under the terms and conditions of the Creative Commons Attribution (CC BY) license (http://creativecommons.org/licenses/by/4.0/). 